\title{
JET FLOW FIELD DURING SCREECH
}

\author{
P. M. SHERMAN, D. R. GLASS and K. G. DULEEP \\ Dept. of Aerospace Eng. \\ The Univ. of Michigan, Ann Arbor, Michigan USA
}

\begin{abstract}
Measurements were made of the flow field structure and the near field parameters of a jet exhausting from a sonic nozzle with a $1.27 \mathrm{~cm}$ exit diameter. Compressed air was used for obtaining stagnation pressures up to $\sim 5$ atmospheres. The jet exhausted vertically from a settling chamber into an acoustically insulated room and through an insulated duct out through the roof. Measurements were made with several different reflecting surfaces at the nozzle exit as well as an insulating surface. Schlieren pictures at $500,000 \mathrm{frames} / \mathrm{s}$ were taken. Overall sound pressure level, impact pressure level downstream, and sound frequency analyzer measurements were made.

It was found that with a reflecting surface there was a radial oscillation of the jet which had the same frequency as the dominant sound (screech) frequency emitted by the jet. No axial motion of the inviscid part of the flow structure was detected. The insulated surface at the nozzle exit appeared to shift the dominant frequencies of the sound generated into the region above the audible $(>16 \mathrm{KHz})$. A reflecting surface yielded "pure tones" (screech) with one or two harmonics. The dominant (screech) frequency decreased as the stagnation pressure increased. The screech frequency was found to be approximately inversely proportional to the length of the first shock cell.
\end{abstract}

\section{Nomenclature}

$C_{0} \quad$ speed of sound in ambient gas

$D \quad$ diameter of nozzle exit

$f \quad$ frequency of pure tone (screech frequency)

$L_{1} \quad$ length of first cell, distance between nozzle exit plane and intersection of shock with shear layer

$M \quad$ Mach number based on isentropic expansion to ambient pressure

$P_{0} \quad$ stagnation chamber pressure

$P_{\mathrm{a}} \quad$ ambient pressure

$P_{\mathrm{i}} \quad$ impact pressure

$R_{\mathrm{LB}} \quad$ distance from nozzle centerline to left boundary of jet

$R_{\mathrm{RB}} \quad$ distance from nozzle centerline to right boundary of jet

$t$ time

$\tau \quad$ period of screech, $1 / f$ 
$X_{\mathrm{E}} \quad$ axial distance of eddy from nozzle exit plane

$X_{\mathrm{I}} \quad$ axial distance of third cell shock intersection from nozzle exit plane

$Y_{\mathrm{I}}$ transverse distance of third cell shock intersection from nozzle centerline

\section{§ 1. Introduction}

Profound changes in the jet mixing process have been shown to result under some conditions [1]. The production of excessive acoustic energy at a particular characteristic frequency is not primarily due to the preferential production of noise within the jet itself, but rather it is due to the preferential amplification of a particular frequency (or frequencies). It appears that a feedback loop is established wherein pressure pulses, which radiate from the downstream portion of the jet, travel through the ambient gas and create disturbances in the jet near the nozzle; these disturbances then interact with the shock structure of the jet as they propagate downstream within the jet. The overall amplification factor of this feedback loop is seemingly not greater than unity except under those particular jet conditions which must exist when "screech" occurs. The amplification of this feedback loop is strongly affected by the reflections of the sound waves near the base of the jet. Although certain elements of this feedback loop are well established, the entire loop has not been adequately defined. Quantitative predictions of frequency and intensity of the screech are generally not possible. In fact, the existence or absence of screech from a supersonic jet in many cases cannot now be predicted.

Most of the work done in attempting to rationalize and predict the entire jet noise phenomena has been somewhat random and grossly empirical in nature. This pertains primarily to measurements made, but also applies to much of the theory. The mathematical theory has not, unfortunately, provided a clearcut guide for quieting engines. The quieting techniques employed have been motivated by conflicting interpretations of the theory, and have met with only a fair degree of success. Furthermore, the explanation of successful muffler behavior is still a matter of speculation. Comparatively little theoretical work has even been attempted in connection with the special problem of the noise from choked nozzles.

While the generation of noise by subsonic jets is fairly well understood much infornation is still to be desired, especially for the higher Mach number subsonic jets. Although Lighthill [2,3] established an analytical description of the generation of aerodynamic noise some time ago, 
theoretical prediction of the noise produced for any given nozzle with known flow parameters appears far off. Many measurements have been made, however, which confirm in a qualitative way the eighth power of the velocity theory for the acoustic power generated. Ribner [4] presents a good summary of subsonic jet noise work.

In supersonic jets, the interaction between the shock structure and convected turbulent eddies, the oscillations of the shocks themselves and the interaction of the jet structure with the radiated sound fields in the ambient gas, all complicate the problem. Ollerhead [5] and others [6] attempted to arrive at some empirical relations for the prediction of the near noise field for supersonic jets but in general concur in the present evaluation of the state of the field, namely, that that there is no reliable technique for the prediction of the near noise field for even the most idealized conditions for rocket or turbojet engine exhausts. Some studies have been made of limited aspects of noise generation from choked jets. Hammitt [8], using spark schlieren and microphones with a twodimensional jet, showed that externally produced acoustic waves can indeed change the shock structure in the jet. The ability of a supersonic jet to emit very loud signals with a spectral peak of certain characteristic frequencies was discussed only briefly by Lighthill [9]. Powell [10,11] did early work on the sound produced by choked jets. He concluded that the frequency of the screech produced was related to the distance between shocks (cells). Why discrete jumps in the frequency occurred with axisymmetric nozzles at certain pressures was not at all explained. Davies and Oldfield [12] did further work on the tones emitted by choked jets. They suggested that the sound generated by the 4th to 7th shock cells created a disturbance at the nozzle exit by propagating upstream in the ambient gas so that a reinforcement or amplification or "resonance" occurred. Westley and Woolley $[13,14]$ used microphones to study the near sound field of a choked axisymmetric jet. Surveys were made of sound pressure levels and screech frequencies. Schlieren techniques were used to photograph jet oscillations. The conclusions possible as a result of all these studies are indeed very limited. Many of the studies suggest work which should be done rather than provide solutions.

Measurements of the fluctuating turbulent stresses in the shear mixing layer (the source of quadrupole radiation) have been made $[15,16]$. Of particular interest are measurements [17] which indicate that the sound generated by a jet can be related to large scale ordered eddies. This latter work with a subsonic jet suggests large scale vortex trains with a preferred 
Strouhal number of 0.3 for the sound generated. The large scale eddies are also observed with supersonic jets under certain conditions [Ref. 12, 13 , etc.].

The measurements reported herein were directed toward obtaining more information for the understanding of feedback phenomena.

\section{§ 2. Experimental procedures}

Fig. 1 shows the experimental arrangement used. The $3.05 \times 4.27 \times 3.96$ $\mathrm{m}^{3}$ high acoustically insulated cell provides for the jet exhausting upward through the roof. The $1.27 \mathrm{~cm}$ converging nozzle is mounted on a settling chamber which is $.30 \mathrm{~m}$ in diameter, $.91 \mathrm{~m}$ long, and contains smoothing screens and noise absorbing surfaces as well as pressure and temperature instrumentation. The nozzle exit is near the center of the insulated cell. Exhaust pipe, floor and the settling chamber were acoustically insulated. Compressed air at nearly room temperature was employed for these tests.

Measurements of the jet structure were primarily made from schlieren photographs taken at 500,000 frames/s. Some measurements were also made of sound pressure level, jet centerline stagnation pressure and frequency spectra with several different reflecting surfaces. Temperatures and pressures in the settling chamber were continuously monitored. The pitot tube was positioned as shown in Fig. 2 and the microphone was placed at $45^{\circ}$ to the axis, $29.2 \mathrm{~cm}$ from the center of the nozzle exit plane. The frequency analysis was done with a Hewlett Packard 3580A Spectrum Analyzer and a $.64 \mathrm{~cm}$ Bruel and Kjaer Type 4135 microphone which has a flat response out to about $100,000 \mathrm{~Hz}$.

For a few measurements a thin "cross" divider was fixed inside the nozzle which extended about 2 nozzle diameters from the nozzle exit plane upstream, dividing the nozzle into four equal sectors.

\section{§ 3. Results and conclusions}

The photographs taken at the fast framing rate showed that there was transverse (radial) motion of the shock structure when even a small reflecting surface was placed at the nozzle exit. Fig. 3 is a tracing of a schlieren photograph showing the motion of the shock structure.

Fig. 4 is a plot of the projection on the photograph of the radial displacement of the third cell shock intersection (location B in Fig. 3) as a function of relative time based on measured screech frequency. The motion of the intersection is shown for the case when a flat disk $12.7 \mathrm{~cm}$ in diameter is placed coaxially with the nozzle as opposed to the motion 


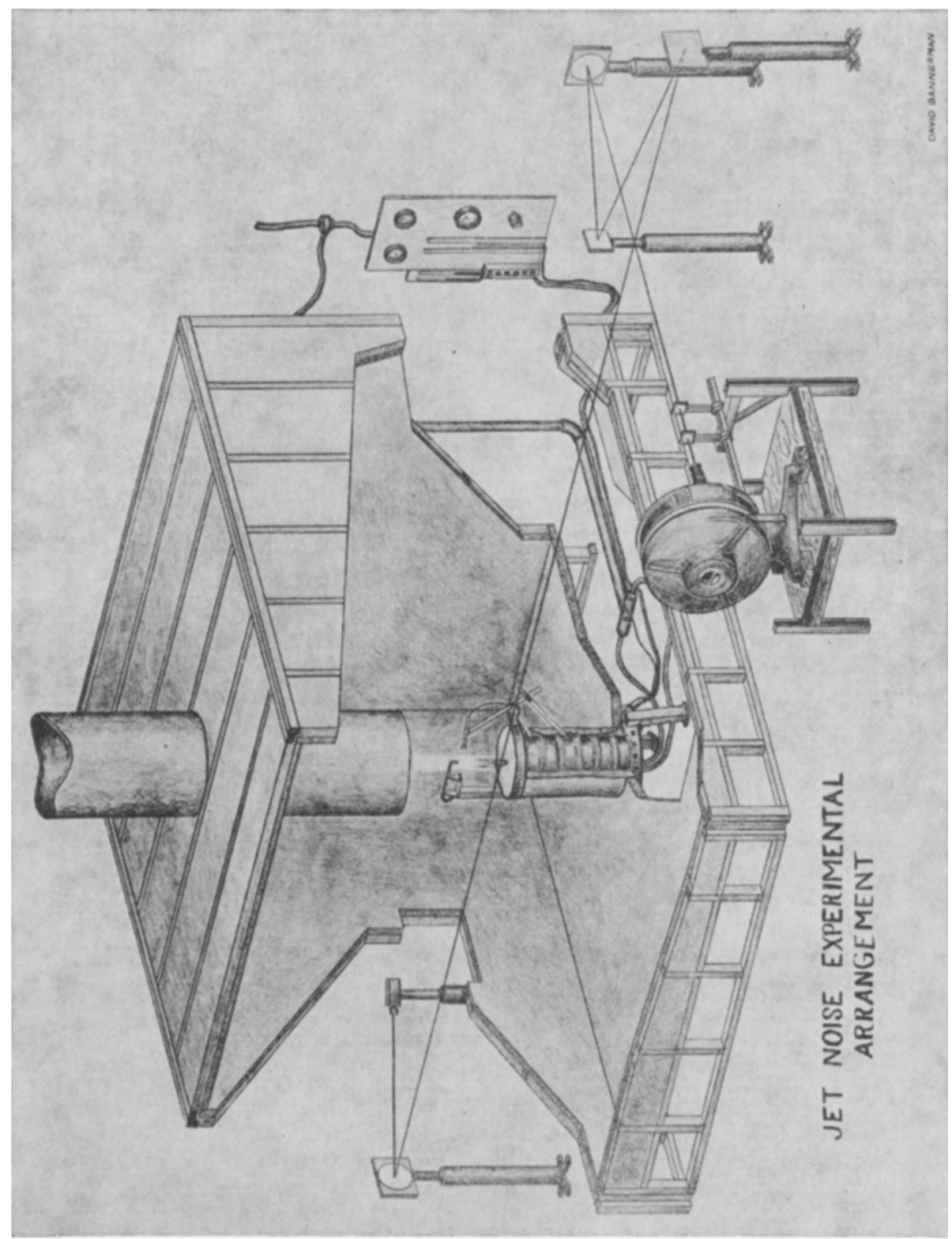

Fig. 1. Sketch of laboratory arrangement. 


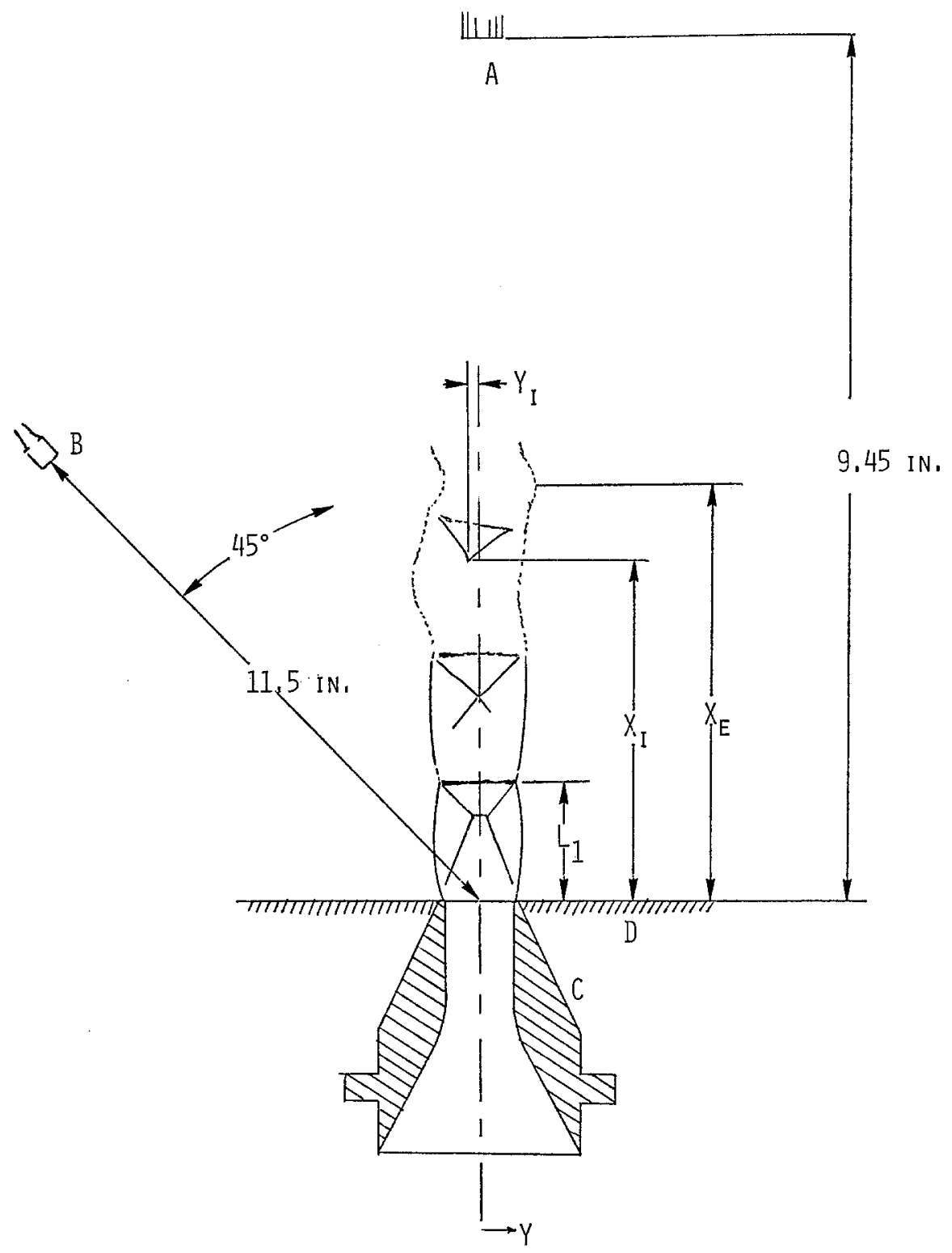

Fig. 2. Experimental layout - A. impact probes; B. microphone; C. nozzle $(1.27 \mathrm{~cm}$ diameter); D. reflector or insulation plane. 


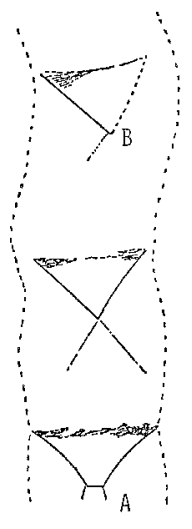

$\tau / \tau=0$

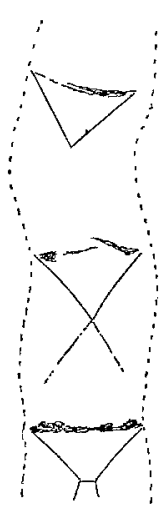

$T / \tau=1 / 3$

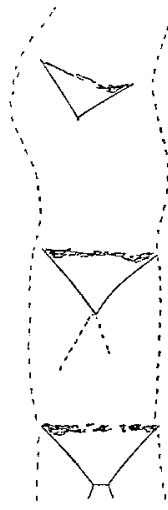

$T / \tau=2 / 3$

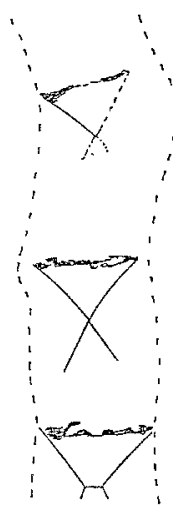

$\mathrm{T} / \mathrm{T}=1$

Fig. 3. Sketch of schlieren photographs showing radial motion of jet structure as a function of relative time. First shock intersection at A, third cell shock intersection at $\mathrm{B}$.

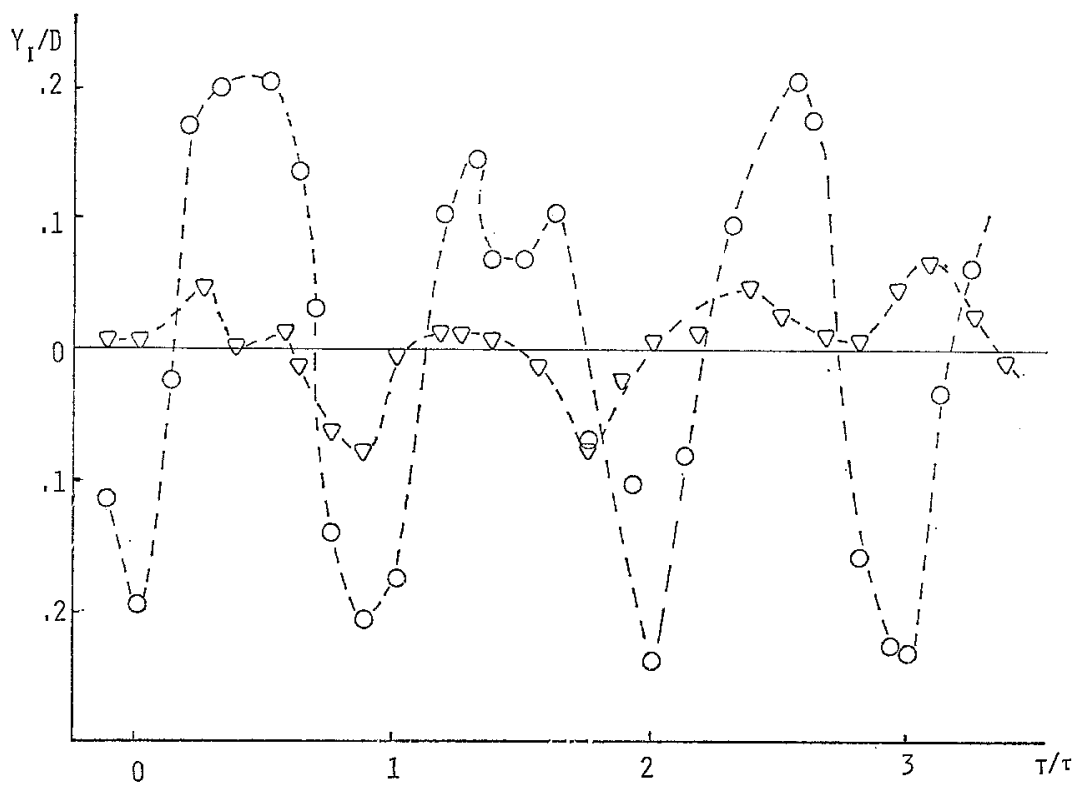

Fig. 4. Transverse displacement (projection of radial displacement) of third cell shock intersection, $Y_{I}$ divided by nozzle exit diameter, $D$, as a function of relative time, $t$, divided by the period of the screech, $\tau$. Circles represent measurements with $12.7 \mathrm{~cm}$ diameter reflector; triangles with insulation at nozzle exit. 


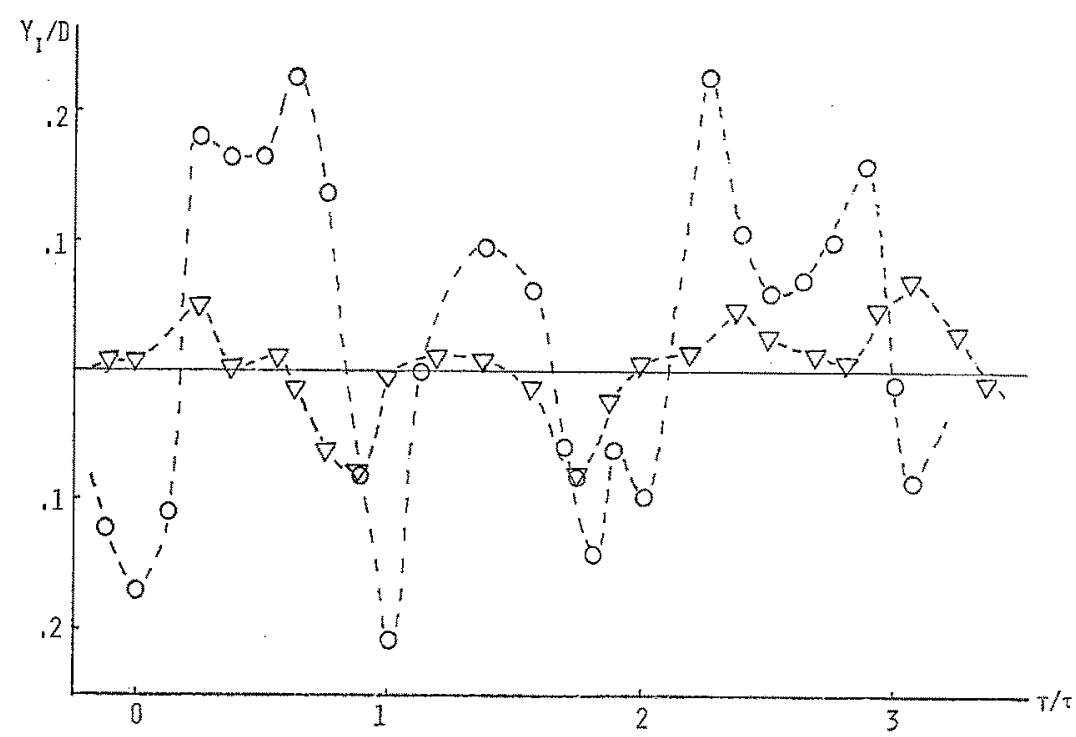

Fig. 5. Same as Fig. 4 but with curved reflector.

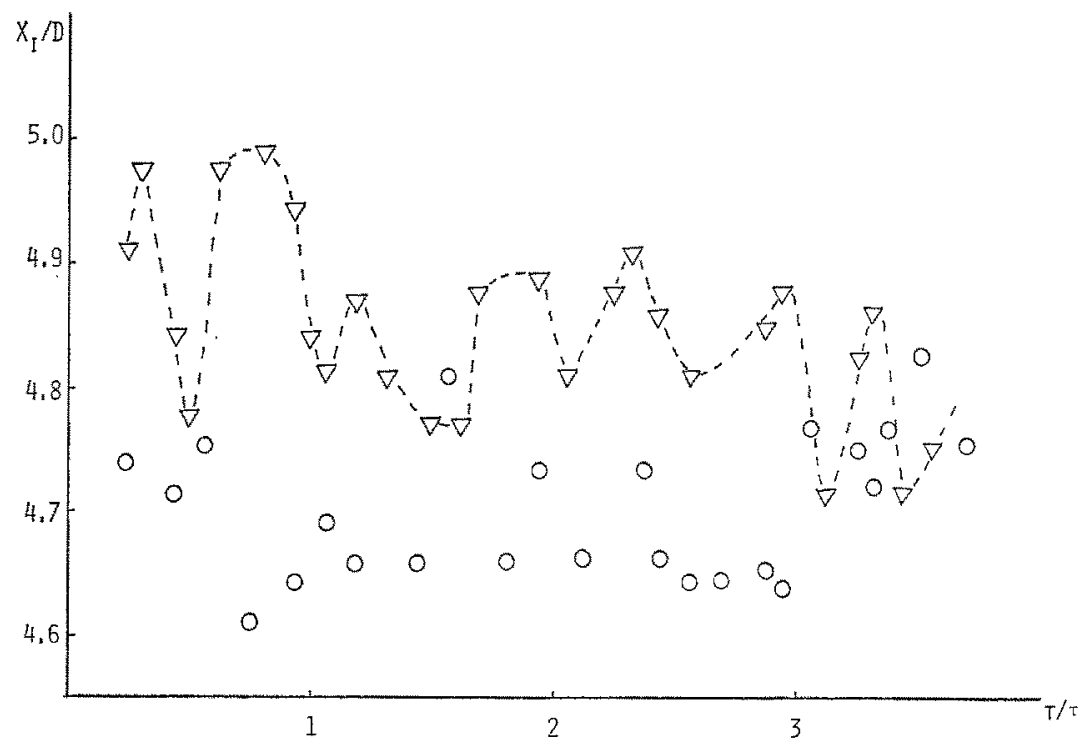

Fig. 6. Axial displacement of third cell shock intersection, $X_{\mathrm{I}}$, divided by nozzle exit diameter, $D$, as a function of relative time $t$, divided by the period of the screech, $\tau$. Triangles represent measurements with $12.7 \mathrm{~cm}$ diameter reflector; circles with insulation at nozzle exit. 
when insulation is placed in the same location. It can be seen that the motion appears to approximate an oscillation frequency like that of the screech. Fig. 5 shows essentially the same effect when a curved reflector (section of a $7.62 \mathrm{~cm}$ diameter cylinder with axis perpendicular to jet axis) is employed in place of the flat one.

It had been expected that there would be some axial motion of the flow field structure which would be related to the screech. This is not apparent from the data. Fig. 6 shows axial motion of the third cell shock intersection as a function of relative time based on screech frequency. Unlike the pattern shown in Figs. 4 and 5 for radial motion, the axial motion does not appear to be well correlated.

As might be expected the radial motion of the shock structure is carried over to the motion of the boundary of the jet itself. Fig. 7 shows the instantaneous radial displacement of the left and right jet boundaries (at a

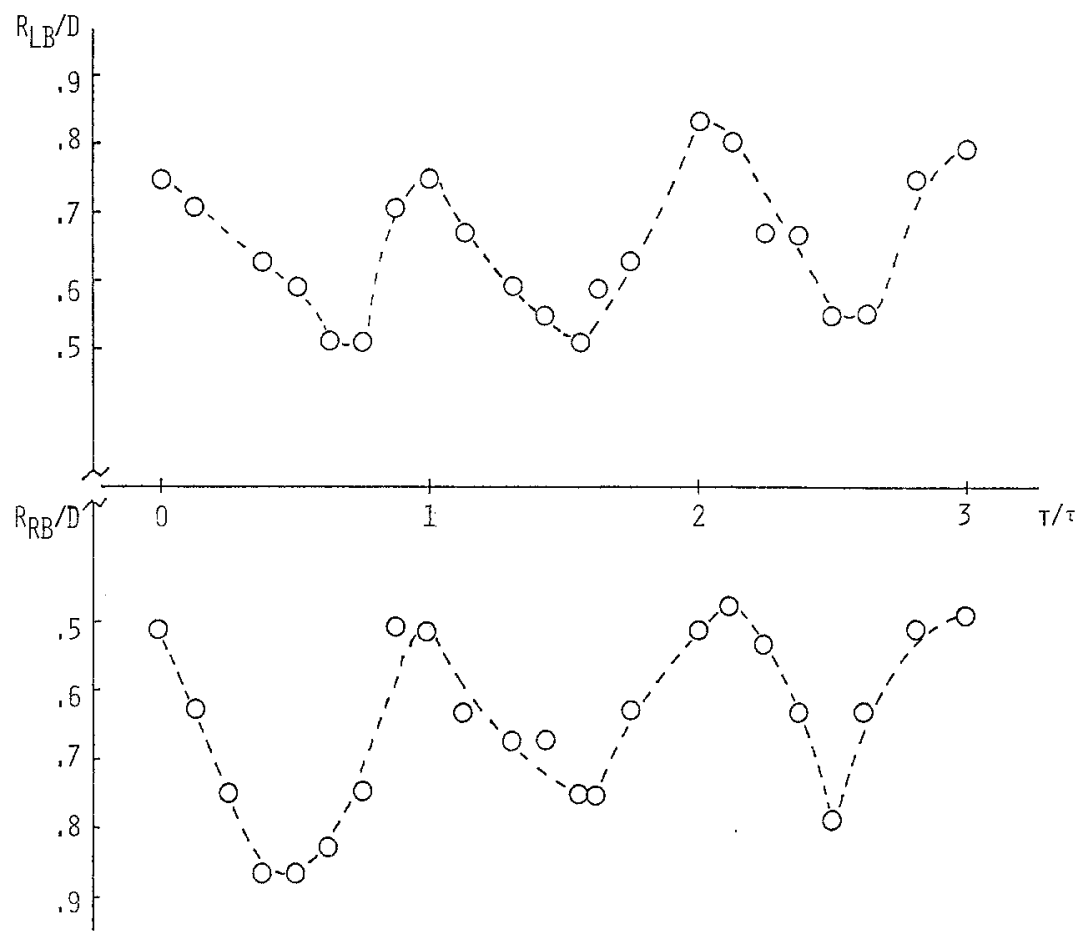

Fig. 7. Transverse displacement from centerline of left jet boundary, $R_{\mathrm{LB}}$, and right jet boundary, $R_{\mathrm{RB}}$, divided by nozzle exit diameter, $D$, as a function of relative time, $t / \tau$. (Distance from nozzle exit is $\sim 3.6 D$.) 


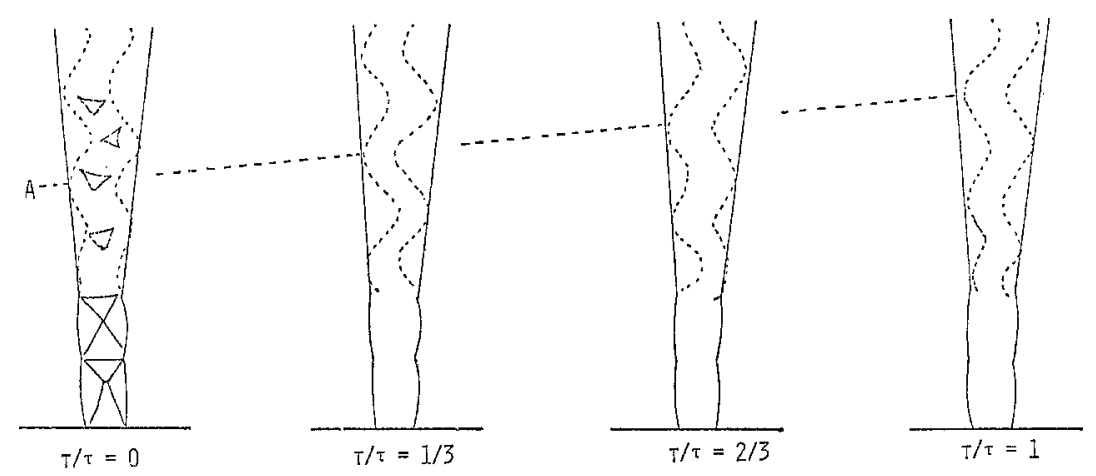

Fig. 8. Sketch of schlieren photographs showing axial motion of eddy A.

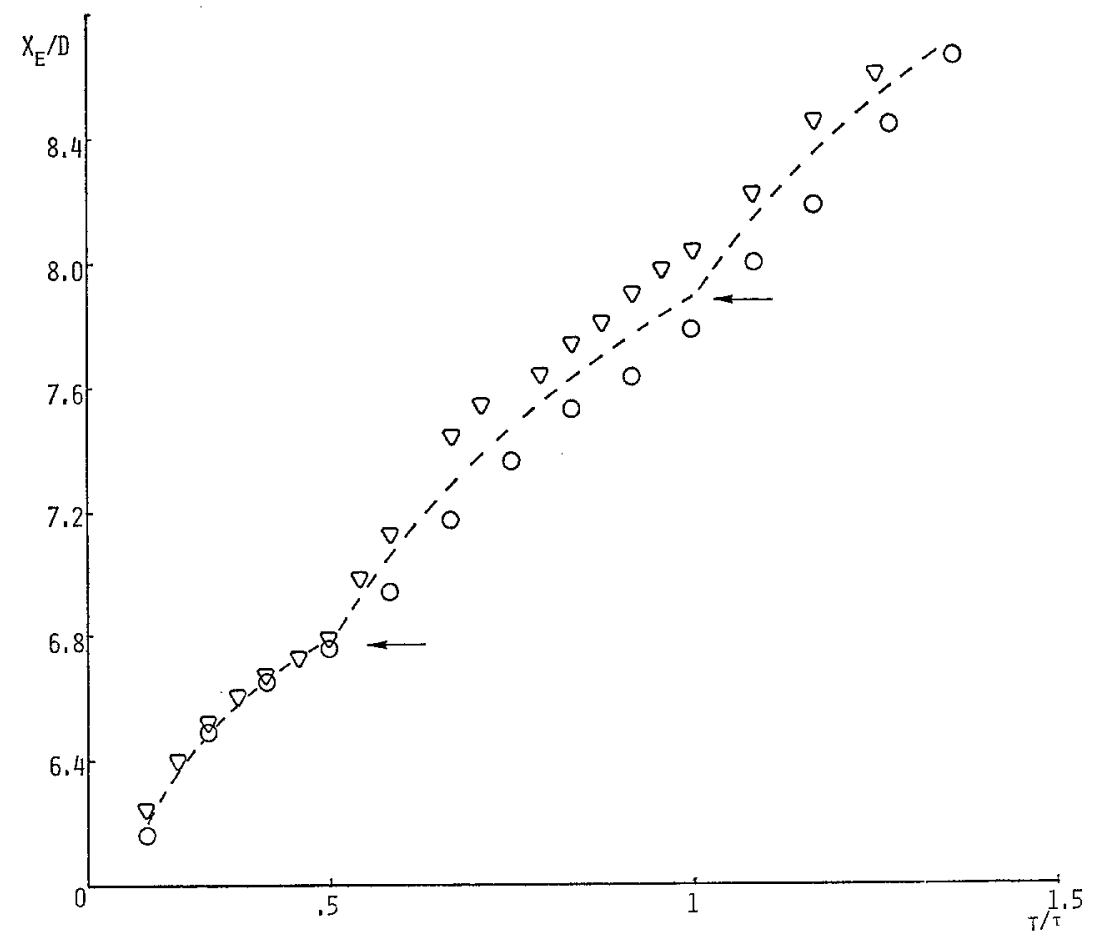

Fig. 9. Axial displacement, $X_{\mathrm{E}}$, of eddy divided by nozzle exit diameter, $D$, as a function of relative time $t / \tau$ with the $12.7 \mathrm{~cm}$ diameter reflector. Arrows indicate the approximate position of the end of the fourth and fifth cells. 
fixed distance downstream of the nozzle exit plane), as a function of relative time. It can be clearly seen that the motion has a frequency equal to the screech frequency.

In addition to showing radial motions the high speed photographs showed the axial convection of a "localized chunk" of fluid following the

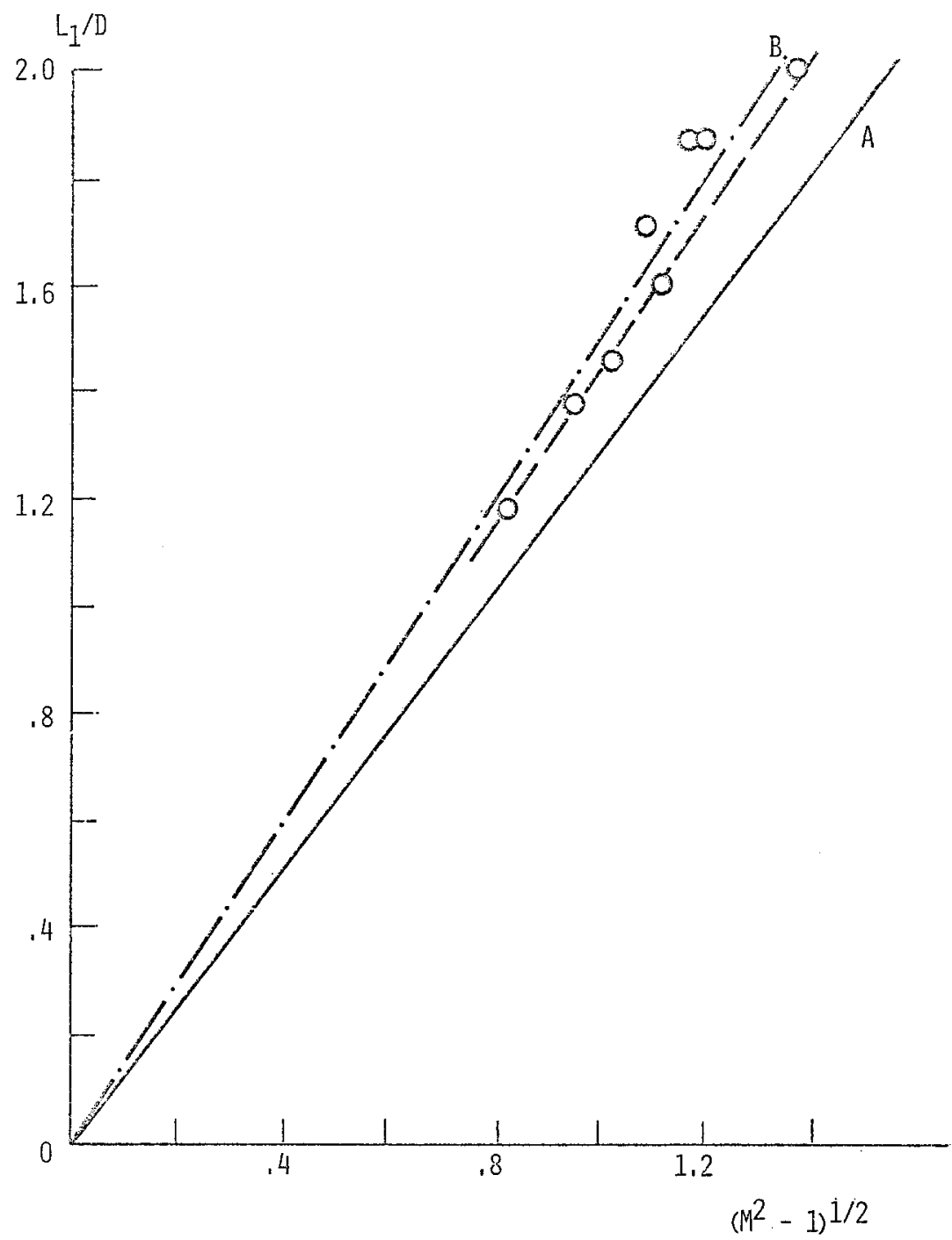

Fig. 10. Length of first cell, $L_{1}$, divided by nozzle exit diameter, $D$, as a function of $\left(M^{2}-1\right)^{\frac{1}{2}}$. Curve A based on Ref. 18; Curve B on Ref. 12. 

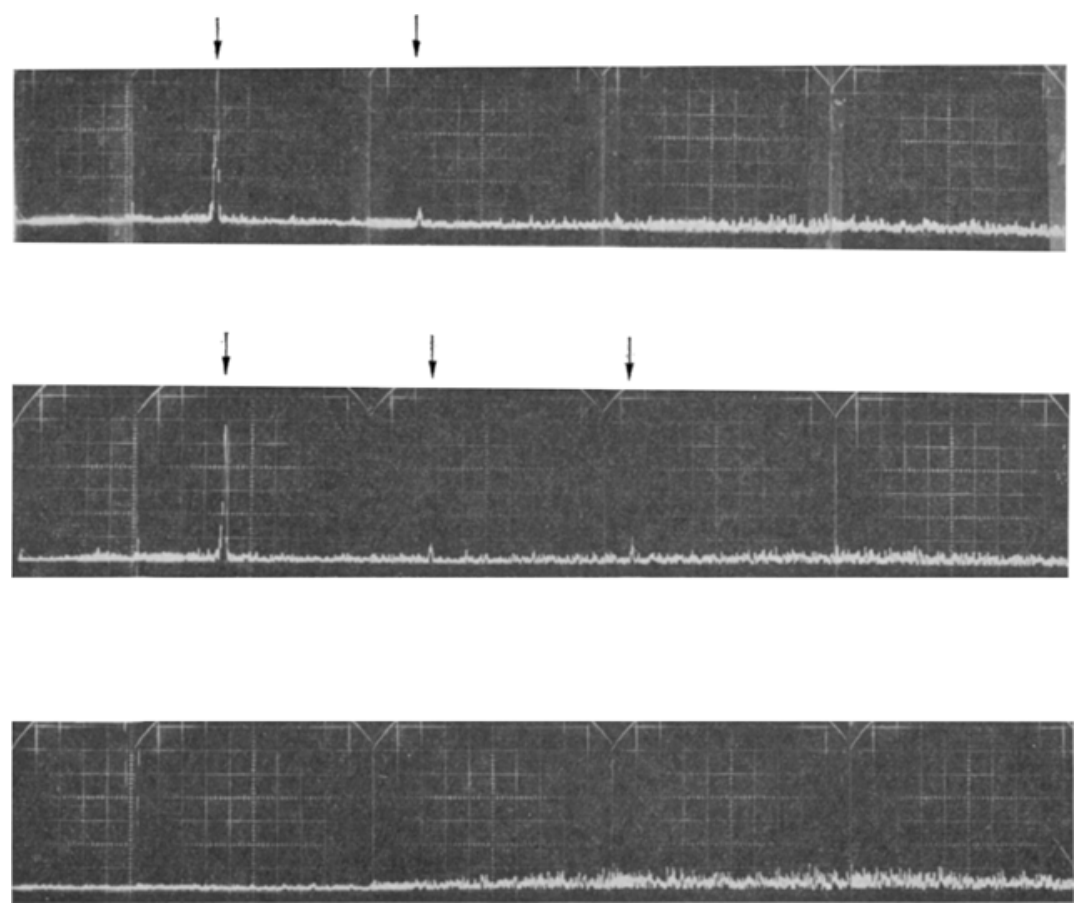

Fig. 11. Relative sound intensity as a function of frequency with $100 \mathrm{~Hz}$ bandwidth. $0-45 \mathrm{KHz}$ range, $1 \mathrm{KHz}$ per division. Top, $12.7 \mathrm{~cm}$ diameter reflector; middle, curved reflector; bottom, insulated surface at nozzle exit plane.

outer edge of what appears to be a helical eddy generated at the boundary of the jet. Fig. 8 is a tracing of the photographs used. Fig. 9 shows the eddy axial motion as a function of relative time for two different runs (with the $12.7 \mathrm{~cm}$ diameter flat reflector in place). It is interesting to note that the velocity of the eddy appears to decrease as the cell end is approached and then increase on passing the cell end position. The average axial component of this velocity, however, is approximately .7 to .8 of the jet exit velocity, as generally accepted [13, 14].

It has been suggested that the first cell configuration is an important one. The non-dimensional length of the first cell as measured from the photographs is compared in Fig. 10 with earlier measurements [12] and predictions [18]. The length plotted as a function of $\beta \equiv\left(M^{2}-1\right)^{\frac{1}{2}}$ shows the points to be not far different from earlier predictions [11] but with a somewhat steeper slope than more recent predictions [13]. 

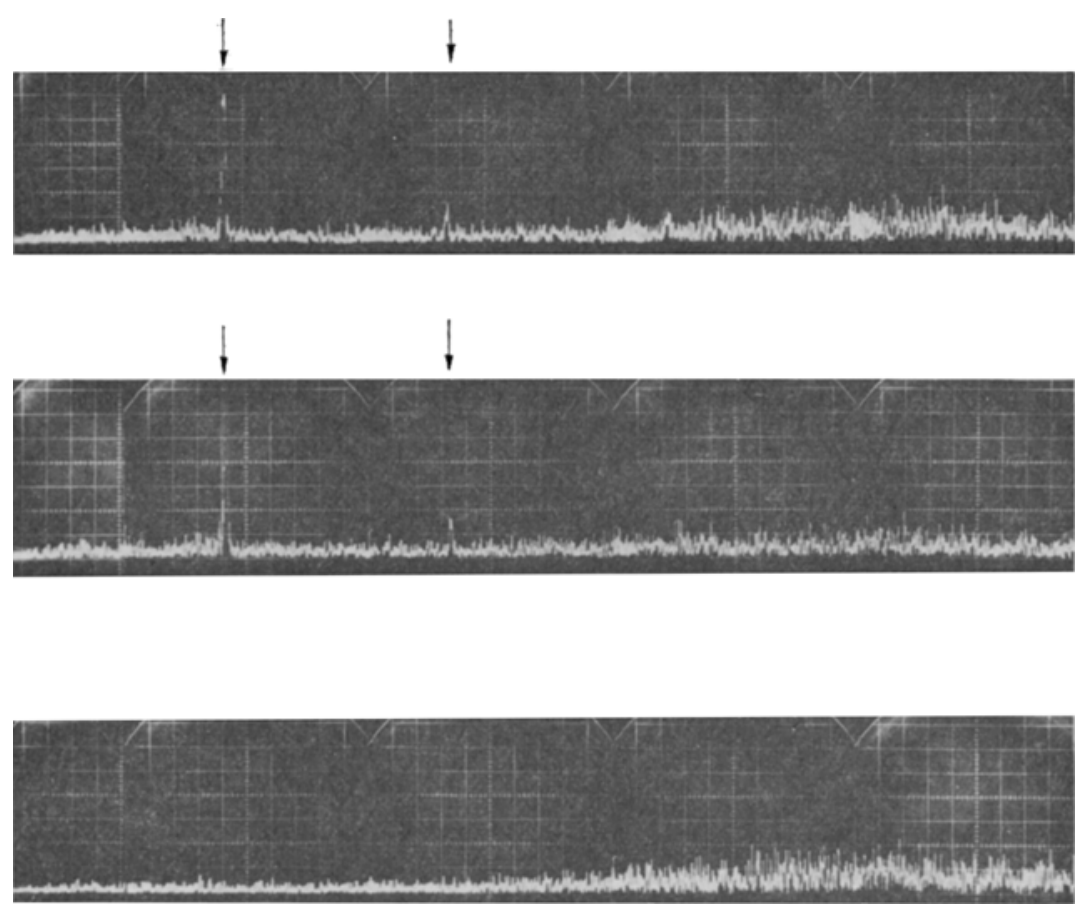

Fig. 12. Same as Fig. 11 but with 4 sector nozzle divider in place.

The frequency analysis (relative intensity versus frequency) of the noise generated is shown in Figs. 11 and 12 over the frequency range $0-45 \mathrm{KHz}$. The results are shown for three reflector geometries, the $12.7 \mathrm{~cm}$ diameter flat reflector, the curved reflector, and the insulation surface. For the reflecting surfaces a high peak can be seen at the screech frequency. At twice the dominant (screech) frequency a smaller harmonic peak can be seen. For the curved reffector a third peak at three times the dominant ferquency can be seen. For the insulated case there are no high peaks and there is a shift in intensity from the low (audible) frequency range to the high frequency range which is outside the range of the human ear $(>15,000 \mathrm{~Hz})$.

It is interesting to note that for the same condition as above but with the divider fixed inside the nozzle, the screech frequency shifts (increases) slightly and at the same time the random part of the signal is increased. The decrease at the low frequency end for the insulated nozzle and the shift to higher frequencies is more marked than in the simple nozzle. 


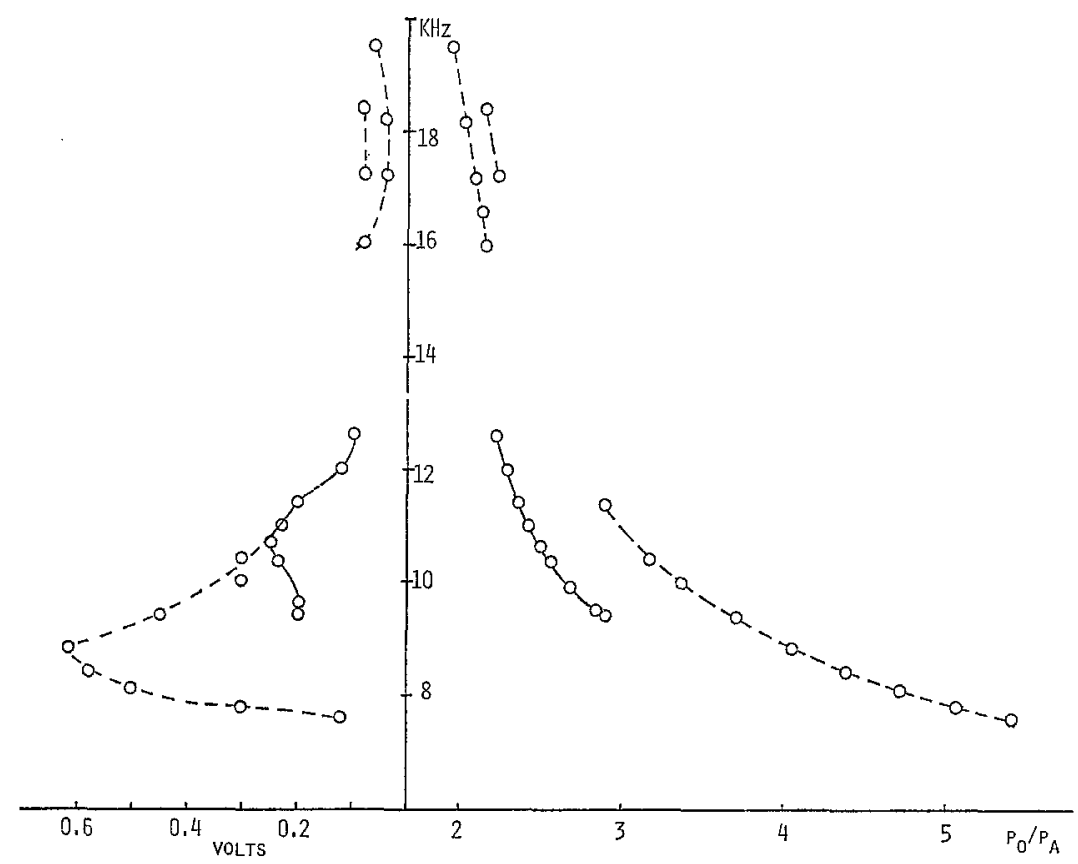

Fig. 13. Relative screech intensity as a function of frequency, $f$, and ratio of stagnation pressure to ambient pressure, $P_{\mathrm{o}} / P_{\mathrm{a}}$; measurements were made with $12.7 \mathrm{~cm}$ diameter reflector and $100 \mathrm{~Hz}$ bandwidth.

The peak frequency and its relative intensity is shown in Fig. 13 as a function of the ratio of stagnation chamber pressure to ambient pressure with the $12.7 \mathrm{~cm}$ diameter flat reflector in place. The measurement bandwidth was $100 \mathrm{~Hz}$. Although there are sections of the curve which are double valued in frequency as a result of jumps, in general, as the stagnation pressure increases the screech frequency decreases. At a pressure ratio of $\sim 4$, the intensity of the screech has a maximum. In Fig. 14 the screech frequency as a function of stagnation pressure is shown for several geometries. The results are approximately the same for the two different reflectors. When the divider is fixed inside the nozzle the curves are shifted somewhat. The shift looks like a stagnation pressure loss. That is, a small decrease of about 5 psia in stagnation pressure would make all the curves very close together.

When sound is reflected between two walls, the fundamental resonant frequency is equal to one-half the speed of sound divided by the distance between the walls. It is interesting to note that for the present case the 


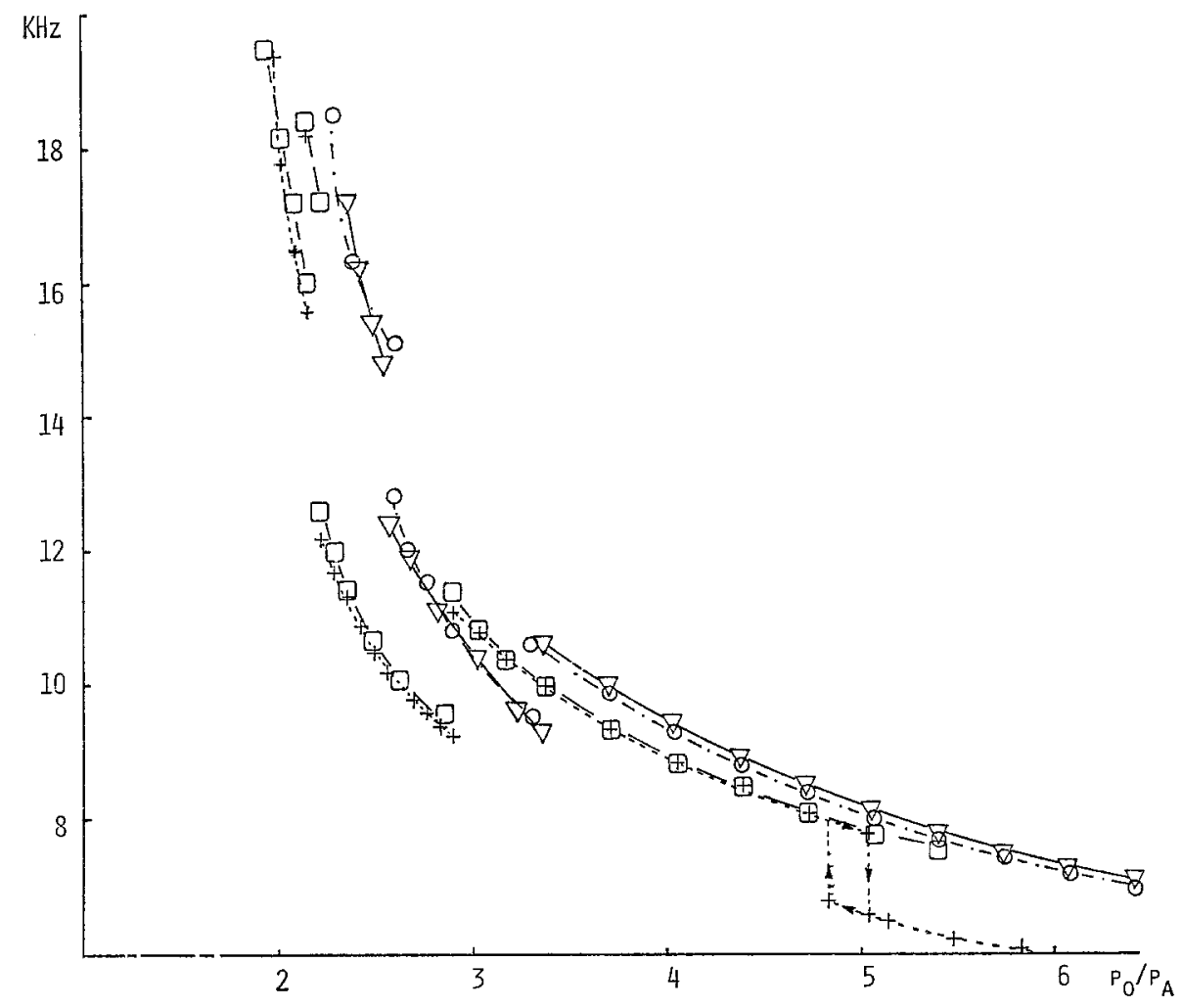

Fig. 14. Screech frequency as a function of ratio of stagnation pressure to ambient pressure for several geometries. Squares and pluses represent measurements with the curves reflector and the $12.7 \mathrm{~cm}$ diameter reflector, respectively; triangles and circles the same conditions but with the 4 sector divider in the nozzle.

resonant (screech) frequency is not far from one-half the speed of sound divided by the distance between the nozzle exit plane and the end of the first shock cell (intersection of shock with shear layer). That is, the screech-frequency is inversely proportional to the length of first shock cell for the region of substantial screech intensity $\left(3<P_{\mathrm{o}} / P_{\mathrm{a}}<5\right)$, see Fig. 15.

It has been shown $[1,7]$ that jumps in frequency are accompanied by jumps in impact pressure downstream. Fig. 16 shows a frequency curve of Fig. 14 with the corresponding impact pressure measured downstream showing the corresponding jumps in frequency and impact pressure. It appears that downstream mixing which determines impact pressure is not 


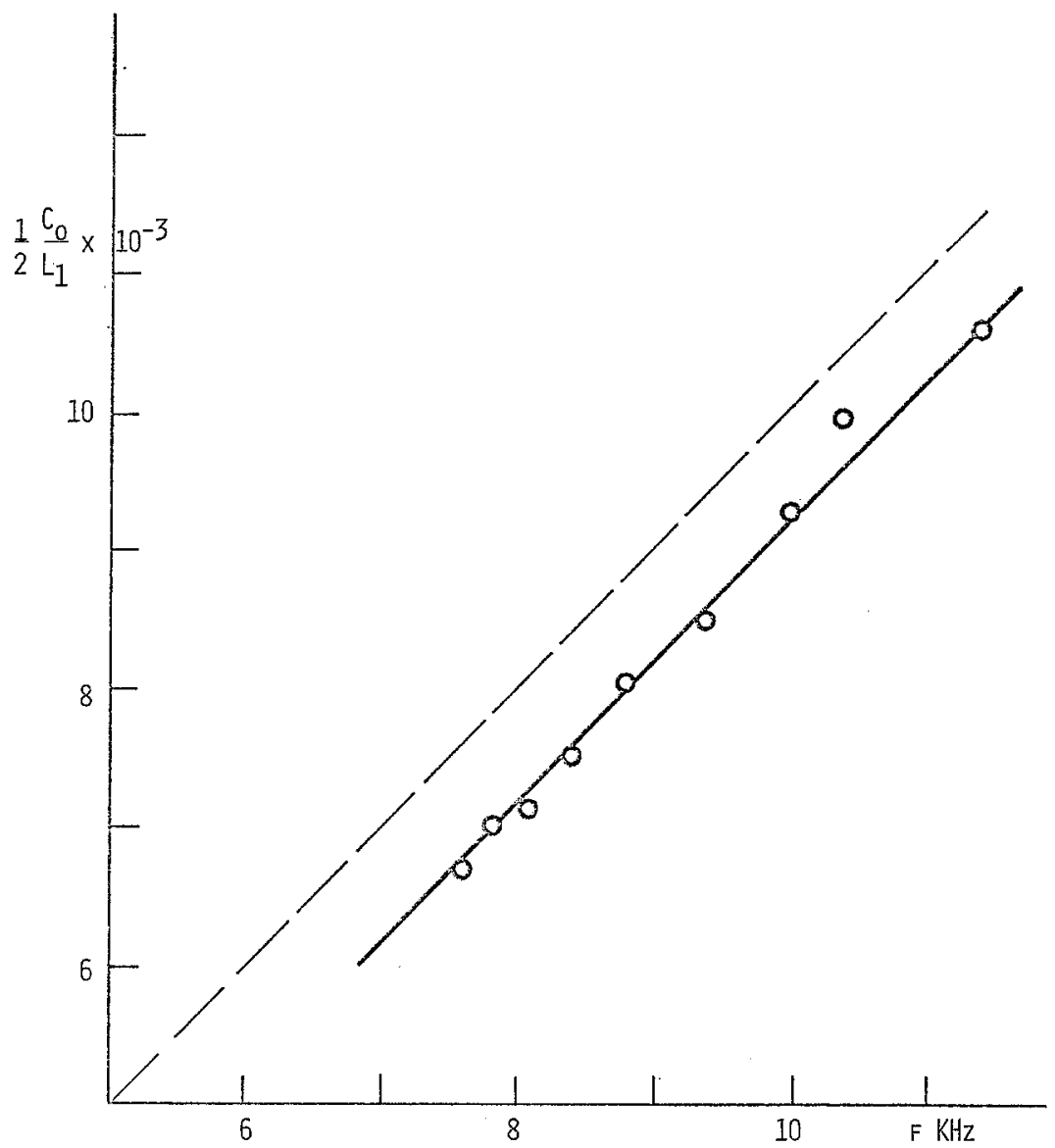

Fig. 15. Screech frequency, $f$, as a function of one-half the speed of sound divided by the length, $L_{1}$, of the first cell.

only related to screech [1] but also to the frequency of the screech. As stagnation pressure is increased to $\sim 5$ atmospheres, the impact pressure and screech frequency both take a sudden drop after which the impact pressure continues smoothly upward while the screech frequency continues smoothly downward. When stagnation pressure is decreased, the impact pressure and screech frequency both take a sudden jump at somewhat less than 5 atmospheres. The sudden changes in screech frequency at about 3 atmospheres and at $\sim 2.2$ atmospheres are also accompanied by changes in impact pressure. Impact pressures for several reflector configurations are shown as a function of stagnation pressure 


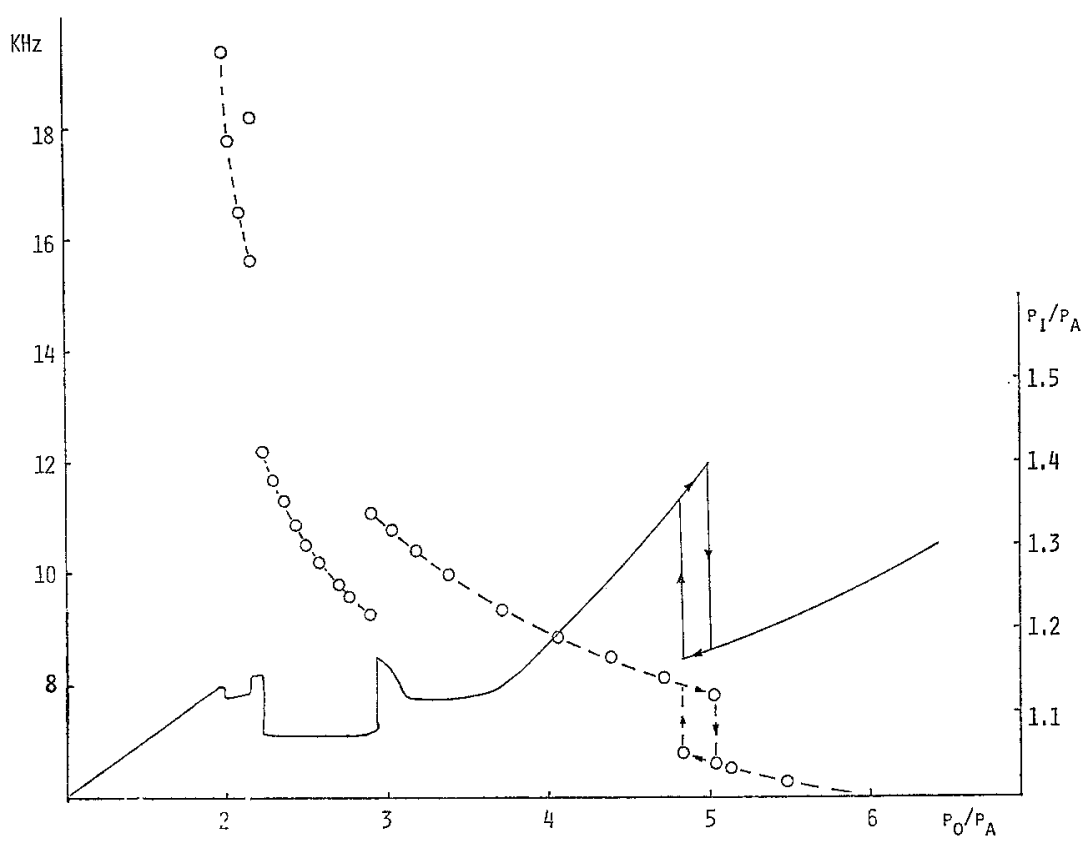

Fig. 16. Screech frequency, $f$, and ratio of impact pressure to ambient pressure, $P_{1} / P_{\mathrm{a}}$, as a function of stagnation pressure.

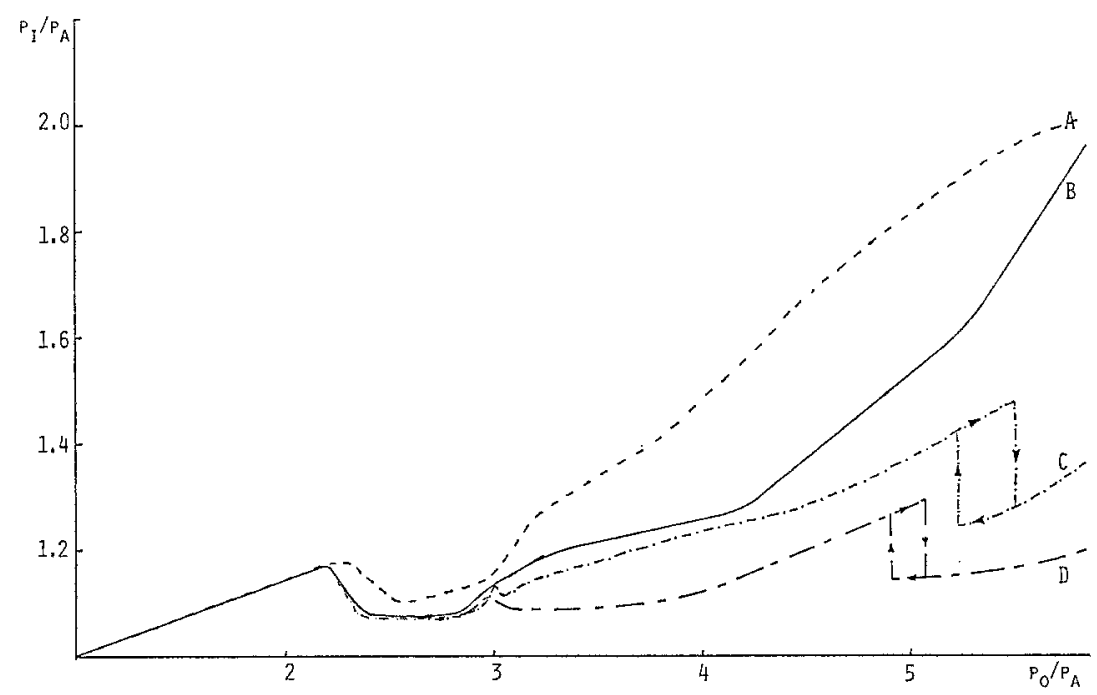

Fig. 17. Impact pressure as a function of stagnation pressure, non-dimensionalized by ambient pressure for several reflector geometries - A. insulated; B. $12.7 \mathrm{~cm}$ diameter reflector; C. $5.08 \mathrm{~cm}$ diameter reflector; D. curved reflector. 


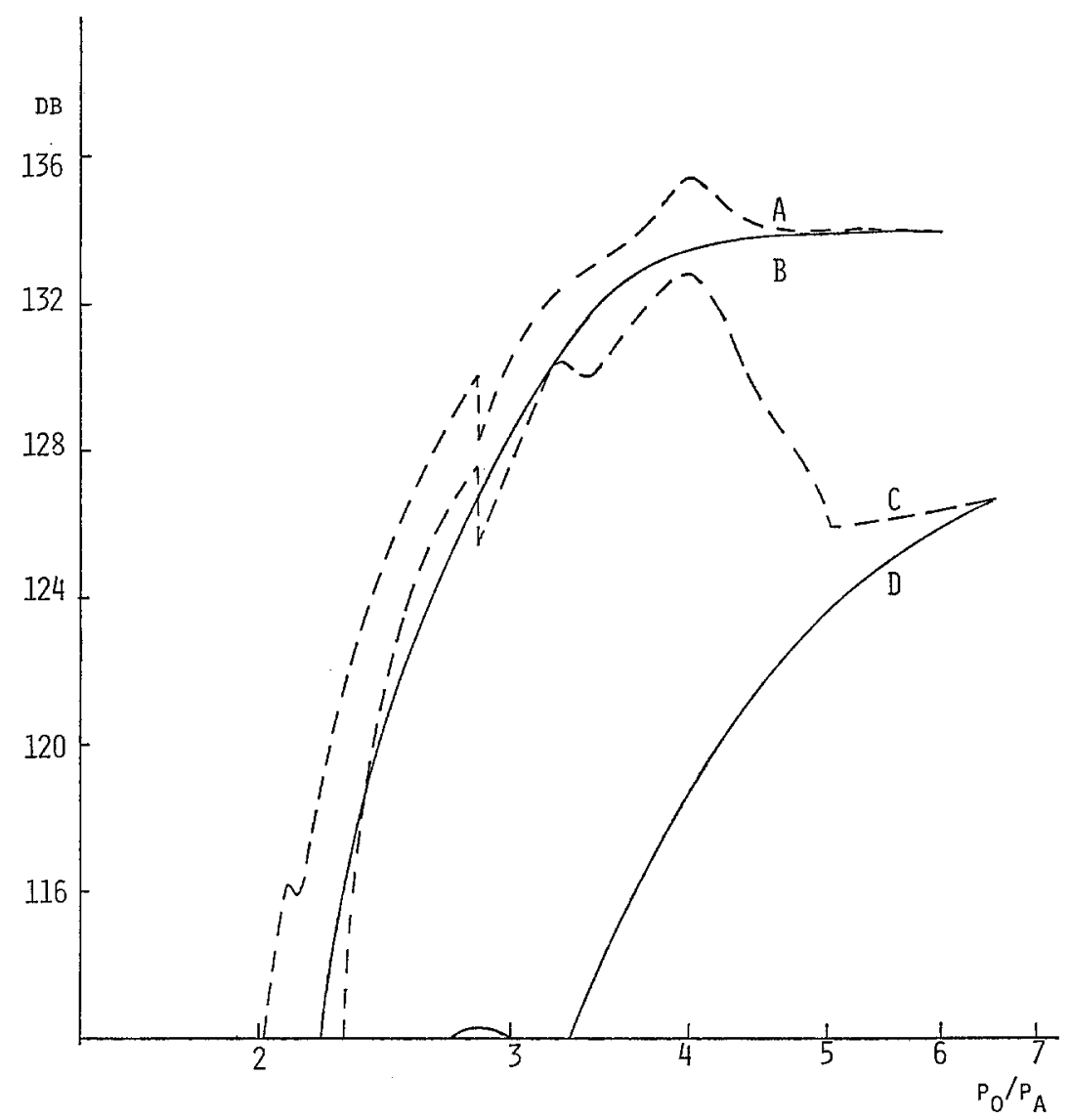

Fig. 18. Sound pressure level as a function of stagnation pressure. Curves $A$ and $C$ represent measurements with the curved reflector; Curves B and D are for the insulated nozzle; Curves A and B represent measurements with a $45 \mathrm{KHz}$ cutoff; Curves $\mathrm{C}$ and $\mathrm{D}$, a $15 \mathrm{KHz}$ cutoff.

in Fig. 17. In general, impact pressure increases with increased stagnation pressure. As might be expected the insulated case would represent the least mixing and therefore shows the highest impact pressure at all stagnation pressures.

Fig. 18 shows the measured overall sound pressure level as a function of the stagnation pressure with the reflector installed as opposed to insulation around the nozzle exit plane. Curves $\mathrm{A}$ and $\mathrm{C}$ are measurements with the curved reflector, Curves $B$ and $D$ with insulated surface. Curves $\mathrm{A}$ and $\mathrm{B}$ have a $45 \mathrm{KHz}$ cutoff. Curves $\mathrm{C}$ and $\mathrm{D}$ have a $16 \mathrm{KHz}$ 


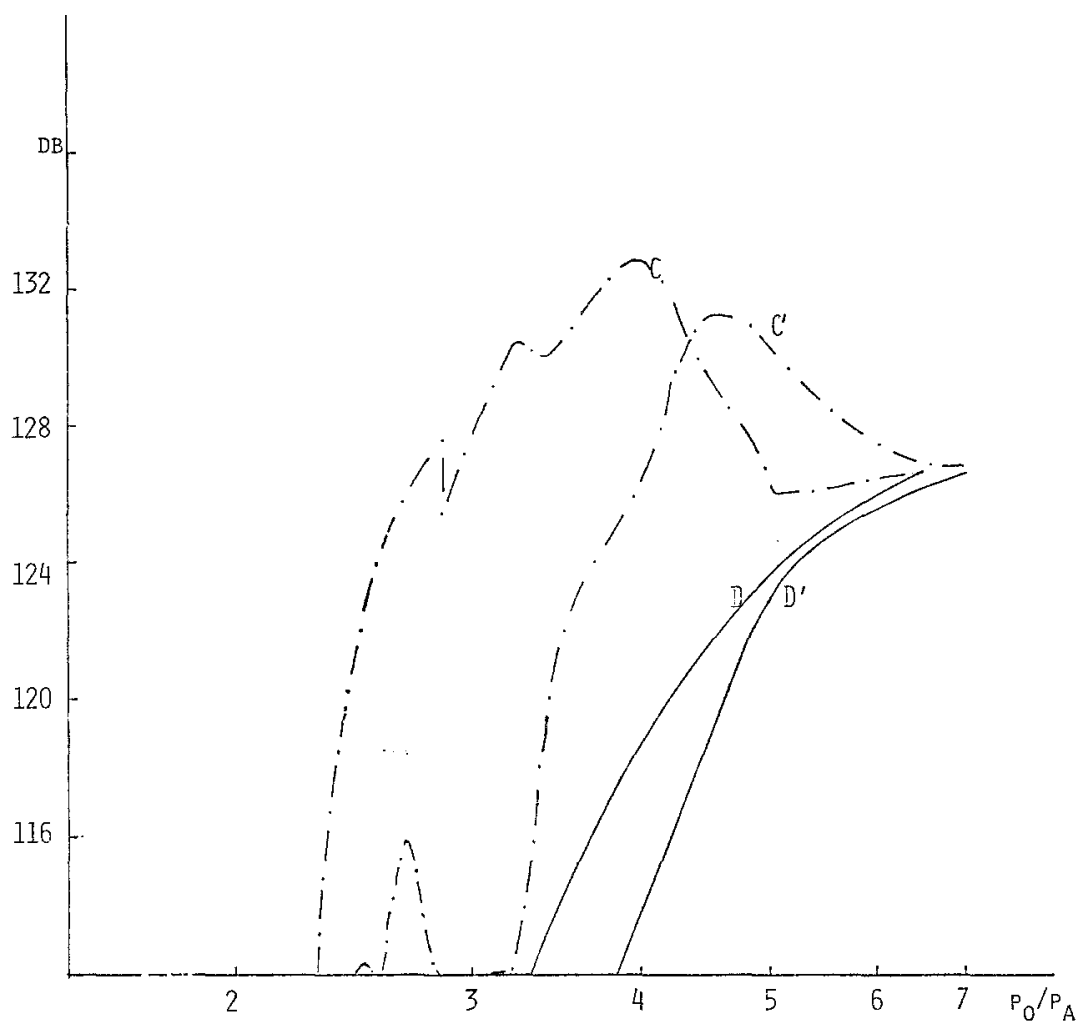

Fig. 19. Comparison of sound pressure level as a function of stagnation pressure for nozzle with and without the four sector divider. Curves $C$ and $C^{\prime}$ represent measurements with the curved reflector; $\mathrm{D}$ and $\mathrm{D}^{\prime}$ with the nozzle insulated; Curves $\mathrm{C}^{\prime}$ and $\mathrm{D}^{\prime}$ are with the four sector divider in place; Curves $\mathrm{C}$ and $\mathrm{D}$ without. Measurements were made with a $16 \mathrm{KHz}$ cutoff.

cutoff. If one compares curves $\mathrm{A}, \mathrm{B}$, and $\mathrm{C}$ for pressures below about 4 atmospheres, there is not much difference in overall sound pressure level. However when the high frequencies are cut out leaving just the audible range (curves $C$ and $D$ ) the overall sound pressure decreases markedly for the insulated case, D, but not for the case with a reflector, $\mathrm{C}$; indicating a large component of the overall noise level is in the high frequency range when an insulation surface is used but not when a reflector is used. This is consistent with what is shown in Fig. 11, where the high intensities are at the screech frequencies when a reflector is used, with a shift to high frequency more random signals, when an insulated 
surface is used. It appears that for the audible frequency range then, the difference in the overall sound pressure level with and without a reflector may be related to the screech intensity shown in Fig. 13. Similar results were obtained for all three reflectors.

Fig. 19 shows the audible sound pressure level for the nozzle with the four sector divider fixed in place (Curves $\mathrm{C}^{\prime}$ and $\mathrm{D}^{\prime}$ ). Curves $\mathrm{C}$ and $\mathrm{D}$ from Fig. 18 are shown for comparison. It appears that in this case, as in Fig. 14, the effect of the divider can be approximately represented by a pressure shift. That is, these measurements with and without the divider would be nearly alike if the stagnation pressure for the nozzle with the divider were adjusted for a loss in pressure, which would result in a shift to lower pressure along the abscissa. However, from Figs. 11 and 12 it is evident that the use of the divider results in higher intensities at higher frequencies.

It has been postulated [8-12] that screech develops as a result of feedback reinforcement. A disturbance convected downstream interacts with the shock structure and results in a disturbance which is propagated back upstream through the boundary which in turn initiates another disturbance at the nozzle exit. A reflecting surface near the nozzle exit would therefore be important in the reinforcement process. Exactly how an insulated surface increases the acoustic energy at higher frequencies while reducing acoustic energy at lower frequencies is not clear.

\section{Acknowledgment}

This work was partially supported by NSF Grant GK 33801 .

Received 7 january 1976

\section{REFERENCES}

[1] GLass, D. R., AIAA J. 6, No. 10 (1968).

[2] Lighthill, M. J., Proc. Roy. Soc. A. 211 (1952) 564.

[3] Lighthill, M. J., Proc. Roy. Soc. (London), A267 (1962) 147.

[4] Ribner, H. S., The Generation of Sound by Turbulent Jets, Advances in Appl. Mech., Vol. 8, Academic Press, N.Y., 1964.

[5] Ollerhead, J. B., Wyle Laboratories, NASA CR 857 (1967).

[6] Nagamatsu, H. T. and G. Horvay, Preprint 70-237, AIAA 8th Aerospace Sciences Meeting, New York.

[7] Nagamatsu, H. T., R. E. Sheer, Jr. and G. Horvay, Basic Aerodynamic Noise Research, NASA SP-207, July 1969. 
[8] Hammit, A. G., J. Aerospace Sci. 28 No. 9 (1961).

[9] Lighthill, M, J., AIAA J. 1 No. 7 (1963).

[10] Powell, A., Aeronautical Quarterly 4 (1953).

[11] Powell, A., Proc. Phys. Soc. (London), Vol. B66 (1953).

[12] Davies, M. G. and D. E. S. Oldfield, Acoustica 12 (1952).

[13] Westley, R. and J. H. Woolley, National Res. Council of Canada, Aeronautical Report No. LR-506.

[14] Westley, R. and J. H. Woolley, NATO-AGARD Conference Proceedings, No. 42, Aircraft Engine Noise and Sonic Boom, May 1969.

[15] ChU, W. T., UTIAS Report 119 (1966).

[16] Davies, P., N. Ko and B. Bose, Ministry of Technology, Aero. Res. Council, CP No. 989, 1967.

[17] Crowe, S. C. and F. H. Champagne, J. Fluid Mech. 8 Part 3 (1971) 547.

[18] Harper-Bourne, M. and M. J. Fisher, AGARD Paper, AGARD CP-131 on Noise Mechanisms, Sept. 1973.

[19] LIU, J. T. C., AIAA 9th Aerospace Sciences Meeting, New York, 1971. 